\title{
Ecosystem-based approach for planning research and capacity development for integrated coastal zone management in Southeast Asia
}

Nidhi Nagabhatla a b, Ngo Tho Hung c*, Luong Thi Tuyen d, Vu Tran Ngoc Cam c, Juliet Dhanraj e, Nguyen Thi Thien ${ }^{c}$, Fredric William Swierczek ${ }^{\mathrm{c}}$

a United Nations University Institute for Water, Health and Environment, Hamilton, Ontario, Canada

$b$ School of Geography and Earth Science, McMaster University, Hamilton, Ontario, Canada

c Asian Institute of Technology Center in Viet Nam, Environment and Development Section, Hanoi, Viet Nam

d Centre for Advanced Research on Global Change, Hanoi University of Natural Resources and Environment, Viet Nam

e Ryerson University, Toronto, Canada

* Corresponding author. Email: hung@aitcv.ac.vn

\section{ABSTRACT}

Coastal ecosystems contribute significantly to socio-economic development in the Southeast Asia Region. The emerging question is how to achieve sustainable development through innovative thinking, smart planning and better insights derived from an ecosystem-based approach (EbA). Based on experience gained while implementing the Sustainable Management and Governance of Coastal Ecosystems (ENGAGE) project funded by the Asia-Pacific Network for Global Change Research (APN), we contribute to addressing this question by proposing an emerging EbA as a complementary concept for implementing Integrated Coastal Zone Management (ICZM). A strong emphasis on strengthening the capacity of development actors and local communities remains pertinent in formulating this eco-centric policy for resource governance. This synthesis is described in three sections presenting an overview of EbA and ICZM in selected countries in the region. The first section reflects the review of coastal management frameworks and institutions, with a focus on policy strengths and gaps in the integration of EbA, particularly in the context of climate change adaptation. The second section explains different procedures adopted or proposed in the region for sustainable development of coastal ecosystems. The third section demonstrates how regional-scale initiatives like ENGAGE can facilitate the exchange of data, information, and knowledge, and stimulate cooperation for realizing the 2030 Agenda for Transformation, and the coastal zone-related SDGs and targets.

\section{KEYWORDS}

Capacity building, Coastal ecosystem, Integrated management, Southeast Asia

\section{DOI}

https://doi.org/10.30852/sb.2019.537

\section{DATES}

Received: 20 March 2018

Published (online): 27 February 2019

Published (PDF): 6 March 2019

\section{HIGHLIGHTS}

» An up-to-date review of the status of coastal management applying ecosystem-based approach (EbA) in the Southeast Asia region.

» EbA is gaining momentum in the Southeast Asian region; accordingly, the capacity for upscaling and implementation is needed.

» Descriptions on how to steer sustainable coastal development through innovative thinking, smart planning and better insights derived from ecosystem-based approaches are crucial.

» Mapping capacity gaps and needs for integrated coastal ecosystem management by involving a variety of stakeholders is pertinent. Aligning conservation and development goals requires sharing existing best practices and case studies that demonstrate the potential for cross-scaling. 


\section{INTRODUCTION AND CONTEXT}

Current debates in sustainability science endorse the need for EbA for resource management and planning. In the context of climate change adaption, the Convention on Biological Diversity (CBD) defined it as "the use of biodiversity and ecosystem services as part of an overall adaptation strategy to help people to adapt to the adverse effects of climate change." As the framework that includes various ecological services and benefits received by communities, EbA, when applied in the context of climate change adaptation planning and natural resource management derives its conceptual underpinnings from consideration of ecosystem services and benefits. The approach also anticipates assisting successful implementation of existing management frameworks vis-à-vis ICZM, while highlighting the need to strengthen stakeholder capacity at all levels of governance and resource management, thereby demonstrating a potential for monitoring and assessing risks in various socio-ecological systems (Nagabhatla et al., 2012).

Recent years have witnessed significant improvements in the development of tools and management frameworks (Hung, Nagabhatla, Tuan, Kathiresan, \& Moon, 2017) and frameworks such as ICZM have proven to be a practical tool for conserving and protecting coastal and near-shore resources. Yet, to better support integrated and efficient management solutions, the need for up-to-date data and knowledge is urgent. ICZM also claims to maximize the integration of multi-sectoral needs as well as minimize conflicts in economic development planning, thus providing flexibility for integrating the synergistic advantages of an EbA. The approach assimilates the principles of sustainable management, conservation and restoration of ecosystems to provide ecological services (benefits) and could enable policymakers and local communities to outline a holistic, integrated and transdisciplinary framework, both for addressing current climate variability and long-term environmental change (United Nations, 2011; Visser, 2004)

Another critical aspect of integrated management is addressing capacity gaps and needs. Recognizing capacity development is a crucial means to implement, manage and restore ecosystem services and further increase awareness of the ecological benefits including the diverse values and cultural significance of coastal ecosystems. Capacity building can enhance the competency of environmental scientists, managers, administrators and communities to evaluate and address the vital questions related to policy choices and the modes of implementation of development options (UNCED \& Johnson, 1993). Chapter 37 of Agenda 21 stresses that the ability of a country to follow sustainable development pathways is noted by its effort to strengthen the capacity of its people, and its institutions (Hens, Borden, Suzuki, \& Caravello, 1998). The 2030 Agenda and the SDG goals and targets are reemphasizing gaps and needs.

The Sustainable Management and Governance of Coastal Ecosystems (ENGAGE) project aimed to strengthen regional-level capacity development in Southeast Asia while addressing the science-policy interface and sustainable development (coastal ecosystems-related SDG goals and targets) implementation needs. The focus on an EbA framework, particularly the synthesis of the status of coastal management and identifying existing best EbA practices at local, national and regional levels are two primary outcomes of the project. The project was designed with activities to strengthen the capacity of selected participants (young professionals, academics, government officials, resource managers) on EbA and ICZM, and to provide a platform for identifying opportunities to integrate EbA into existing coastal management system approaches and strategies (full report of the project is available on the APN website).

The ENGAGE project adopted an innovative twin-framework (training-cum-workshop) model to advance the understanding of ecosystem-based approaches, jointly underline regional priorities and initiate discussions to fill data and information gaps. Experts from Southeast Asia (16 females and 15 males from 6 countries-Viet Nam, Malaysia, Indonesia, Thailand, Myanmar, Philippines and other invited experts from the US, Canada, India, and France) participated in the face-to-face module of the project, representing various disciplines, institutions and sectors as seen in Figure 1. The project team also organized a country scale synthesis on coastal characteristics and threats, status, overview of climate change governance, and how EbA initiatives can serve as a strategy for sustainable management. Cross-cutting aspects in EbA, namely nature-based solutions, water, food security, and disaster risk reduction to reduce the vulnerability of people and simultaneously generate a range of social, economic, and environmental co-benefits were reviewed in tandem.

\section{OVERVIEW OF STATUS OF COASTAL MANAGEMENT IN THE SOUTHEAST ASIAN REGION}

The region has an extensive coastline of nearly 173,251 $\mathrm{km}$ and has the most diverse coral reef ecosystems in the world (Asian Development Bank [ADB], 2009). Endowed with rich biodiversity and ecosystem spread namely mangrove forests, sea-grass and algal beds, estuaries, lagoons, sandy beaches, mudflats, and shallow coasts 


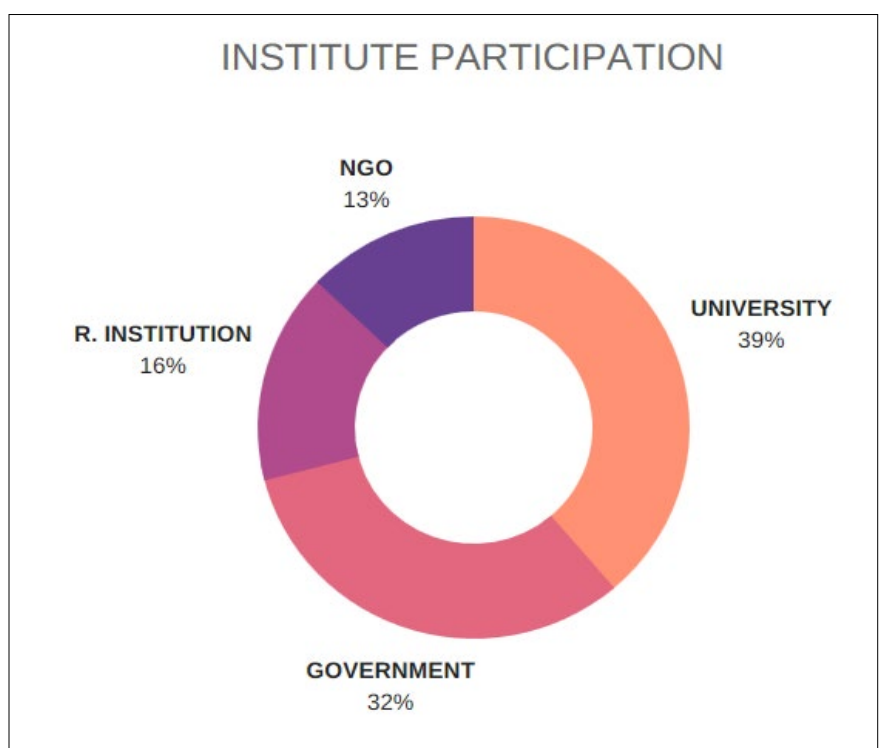

FIGURE 1. Stakeholder distribution in the ENGAGE Programme.

(Veron \& Stafford, 2000). These ecosystems provide a wide range of economic services and benefits to communities inhabiting the coastlines, mainly in the sectors of sea trade, fisheries, fish production, and tourism (Brown, Daw, Rosendo, Bunce, \& Cherrett, 2008). The region is populated by more than 600 million people who depend on coastal and marine resources for their livelihoods and well-being (Hughes, 2017). As a case in point, coastal and marine economic activities are estimated to account for some $25-30 \%$ of Indonesia's GDP while employing about 20 million people (ADB, 2009). The extensive shorelines, characterized by sensitive ecosystems and ecological resources, is being forced to compete with a range of intensive human activities such as settlement, agriculture, tourism, fisheries, mining, and communication. Exposed coastlines in the region face a multitude of stresses, including infrastructure development, harvesting of endangered species, ornamental trading, human-induced environmental degradation and pollution (Tabet \& Fanning, 2012). Natural hazards and disasters such as cyclones and tsunamis, in addition to rising sea level and other anthropogenic pressures have exacerbated the degradation of coastal and marine resources.

The review undertaken by the ENGAGE project proved to be of relevance to recognize the need for future strategies, anticipating that existing and collective knowledge in the region can be scaled up to provide a guiding framework for regional collaboration and capacity development. The increasing and competing demands for coastal resources and ecosystems have led to the adoption of an economics-oriented development agenda in many parts of the world including in Southeast Asia, thereby creating conflicts and disputes between planners, policymakers and local communities, resource-users with economic interests, and conservationists. Often, interdisciplinary and participatory management approaches are not commonly integrated into policy and technological interventions or regulations related to the use of coastal and marine resources. Further, the allocation of coastal and marine resources for economic activities has not been systematically managed and more often unregulated (Wilson \& Tisdell, 2003). Regional trends and patterns of regulatory frameworks show that countries are preparing to address coastal management issues by employing smart management strategies (Hung et al., 2017).

Some examples of regulations in Southeast Asia countries are outlined below:

In Indonesia, Act No. 27/2007 and Act No.1/2014 addresses integrated management of coastal areas and small islands through planning, utilization and supervision involving substantial involvement of the local community.

Malaysia has a five-year plan in place to address mapping the policy and development projects and activities to be adopted by the government, which includes environmentally oriented ordinances and embeds the ICZM framework (Wilson \& Tisdell, 2003). The plan can be accessed at http://www.mof.go.tz/mofdocs/msemaji/ Five\%202016_17_2020_21.pdf.

The government of Myanmar is presently involved in formulating the Bay of Bengal Large Marine Ecosystem (BOBLME) programme that seeks to promote sustainable marine ecosystem management and sustainable coastal livelihood development. The programme aims to improve the lives of coastal populations through the efficient regional management of biodiversity and fisheries.

In the Philippines, Executive Order No. 533 released in June 2006, was issued towards the adoption of ICZM and is considered a future development strategy for coastal areas. To date, $8,265.2 \mathrm{~km}$ of coastline is covered by the programme, which comprised $22.8 \%$ of Philippines' coastline. Currently, local activities are implemented in 479 coastal localities out of a total of 822 (Rebuelta, 2012).

In Thailand, recent laws and enforcement measures initiated by the Department of Marine and Coastal Resources (DMCR) and agencies such as the Marine and Coastal Resources Management Promotion (MCRMP) Act B.E. 2558 has enabled strong leadership in providing local governments with the authority to act and support its national goals. The new fisheries law- the Royal Ordinance on Fisheries B.E. 2558 (2015) along with the recent National Maritime Security Plan (2015-2021) have strengthened the country's portfolio of regulatory measures for coastal and marine protection. 
In Indonesia and Thailand, the impact of tourism is significant (UP-MSI, ABC, ARCBC, DENR, \& ASEAN, 2002). Indonesia's policy of "open access" to people for coastal areas and small islands, is aimed at more diverse and competitive resource utilization activity (Hung et al., 2017). Coastal degradation in Malaysia is mostly due to rapid and ad hoc development, as well as economic expansion plans that are often intense land-based activities such as coastal construction. The relatively low tourism impact in Malaysia could be an underestimation or a strategy adopted to conceal the full extent of environmental degradation often associated with tourism development (Hung et al., 2017).

In Viet Nam, the Government Decree No. 25/2009/ ND-CP calls for integrated management of resources and marine environmental protection and serves as a regulatory framework for ICZM implementation. Coastal provinces of Viet Nam actively promulgate legal regulations to guide and direct sustainable management. For example, the regions of Thai Binh, Hai Phong, Quang Ninh, Nam Dinh, Soc Trang, and Kien Giang have mechanisms to address challenges related to coastal ecosystems, even though they differ in practices adopted. Despite the availability of human, financial and technical resources for coastal resource management, enforcement and monitoring of activities are overburdened due to multiple responsibilities and insufficient support. In the Mekong basin, mangrove forests have been profoundly degraded both in area coverage and quality, particularly in the southern Mekong Delta. In Viet Nam, mangrove forests shrunk from 400,000 ha in 1950 to 270,000 ha in 2015. The impact of activities such as intensive fishing is reported to have severe impacts on coastal ecosystem services in Viet Nam (Hung et al., 2017).

Conversion of mangroves for export-oriented intensive shrimp production also remains a substantial threat in many parts of the region (Food and Agriculture Organization of the United Nations [FAO], 2016). Overall in the region, the impending impacts of climate change and environmental degradation add to the existing pressures faced by coastal ecosystems if sustainable use and management guidelines are not adopted.

A coordinated framework for coastal zone management at the regional scale can benefit a futuristic vision of ICZM in the region.

In the context of gaps and needs, some key points are highlighted. In Viet Nam, EbA adoption is not widespread because of a substantial gap between theoretical understanding and practical applications (Institute of Strategy and Policy on Natural Resources and Environment [ISPONRE], 2013). In general, contradictions in the legal instruments pose problems for implementing EbA projects. Initiatives in the Philippines are mostly governed, through local efforts, by cities and provincial governments. For example, Puerto Princesa in the province of Palawan, organizes a community- based celebration termed 'Love Affair with Nature' for the protection of coastal resources every year on 14 February. Indonesia's Coastal Education Programme provides mentoring activities for youth and students at local and provincial levels.

Overall, the synthesis reflects on existing solutions with a focus on EbA. It further provides references to Nature-based Solutions (NbS), i.e. 'living solutions inspired by, continuously supported by and using nature designed to address various societal challenges in a resourceefficientandadaptablemanner toprovidesimultaneously economic, social and environmental benefits' (Maes \& Jacobs, 2017). NbS was considered more so in the context management of mangrove ecosystems. The need for understanding EbA towards designing and planning interventions for the sustainable management of coastal and marine resources is highlighted in recent studies (McCue, 2014; Wilson \& Tisdell, 2003). The challenges with many current interventions are that the emphasis is solely placed on engineered solutions that may result in siltation and degradation of aquatic ecosystems. It was also found that integrated planning can help mitigate the effects of natural hazards and enhance coastal resilience. Further, urban areas with high population density integrated planning can also help maintain ecological structures and services (Nagabhatla \& Metcalfe, 2018).

\section{GLOBAL DEVELOPMENT AGENDA AND INTEGRATED MANAGEMENT APPROACHES}

Adoption of participatory approaches involving local communities and other stakeholder groups to collaborate provides a holistic approach with opportunities for active engagement. Communities and decision-makers are interested in environmental impacts (FAO, 2016) and see the need to understand how scenarios of environmental degradation impact their livelihood and income generation prospects ( $\mathrm{ADB}, 2009)$. In the developed world, stakeholder participation is becoming standard practice. Southeast Asia states and communities are also preparing to adopt this bottom-up approach as the norm in their development interventions. The success stories of joint forest or fisheries management produced in the Asian context is well known (SpringateBaginski \& Blaikie, 2007). Formulating planning and policy measures to minimize multiple resource use and users inherent to natural resource systems remains crucial. Additional aspects like failure to recognize and respect rights of ownership, value systems, and local knowledge systems are also important while managing 
multi- stakeholder engagements (Burroughs, 2011). It is a fair assumption that participation and consultation with stakeholders, resource users and managers can positively contribute to achieving desired outcomes and impacts.

Coastal management status in Southeast Asia is tackled well as states are committed to achieving the SDGs while addressing and implementing smart coastal management strategies and the need to develop mechanisms for intergenerational knowledge-sharing networks and communication. The framework to disseminate information and expertise on complex issues can help to provide a clearer understanding of the interconnections and interdependence between local and scientific knowledge, adaptive capacity and bridging of knowledge gaps. Towards this, the ENGAGE project initiated a regional platform/community of practice to facilitate information and knowledge exchange. The social media group developed $>500$ members from the region and has regular exchanges on various topics.

The synthesis provided a potential framework with a wide-ranging portfolio of adaptation measures that employ sustainable management principles, conservation goals, and restoration objectives to ensure the provision of ecosystem services that facilitate human adaptation to the adverse impacts of multiple pressure, including climate change. The synthesis also provided a guiding framework for adopting EbA towards designing and planning interventions for the sustainable management of coastal and marine resources (Hung et al., 2017).

In 2015, the United Nations adopted a new development agenda, the SDGs, which focusses on improving the sustainability of member states. Rio+20 (June 2012) laid out these goals and the 2030 Agenda for transformation. The goals of the 17 SDGs comprising 169 targets is a collective programme to strengthen global governance. Specifically, the vision of Goal 14 is to "sustainably conserve the oceans, seas and marine resources for sustainable development." SDG 14 sets out goals and targets to advance the sustainable use and conservation of coastal and marine ecosystems while developing effective strategies and management to combat the adverse effects of activities vis-à-vis overfishing, coastal eutrophication and over extraction amid other cases of unsustainable anthropogenic interference. Expanding protected areas for managing biodiversity, intensifying research capacity and increasing funding commitment are milestones that remain critically significant to preserve coastal and marine resources (https://sustainabledevelopment.un.org/sdg14).

As countries in Southeast Asia are in the process of developing plans that identify priority areas as well as action plans that address the SDGs, the present synthesis undertaken by the ENGAGE project can be a good source of reference.

\section{THE ENGAGE PROJECT-REGIONAL INITIATIVE FOR STAKEHOLDER DISCUSSIONS ON EbA}

The ENGAGE project initiated a regional discussion by aligning the EbA framework to complement existing management strategies for coastal ecosystems. Integrating EbA with development and climate-related discussions are on the increase. Open dialogue with experts, specialists and policy actors addressed common issues in aligning EbA and development planning is taking place though the creation of a regional multi-stakeholder group. Knowledge from current concepts, new methodologies and traditional practices with a focus on regionally-relevant sustainable management strategies are being shared in consultations with a broad range of stakeholders, including young professionals. A regional-scale review was also initiated to provide information especially where knowledge gaps exist.

The project also created a regional community of practice (CoP) of trained professionals (Facebook group with more than 500 members) who can take forward $\mathrm{EbA}$ as a policy support tool designed for ICMZ and EbA guidelines. The participants (including policymakers and members of local communities) gained knowledge, skills, practical experience, training and technical assistance to develop national-scale initiatives. For example, the participant from Thailand organized a national-scale workshop based on the experience and knowledge gained from participation in the ENGAGE project. Additionally, participants from Thailand, Viet Nam and Myanmar organized exchange visits and joint proposals on topics of common interest (details are on the Facebook page of the ENGAGE project). The initiative also demonstrated how regional-scale initiatives could facilitate exchange of data, information and knowledge, and stimulate cooperation for realizing coastal zone planning and implementation of related SDGs and targets.

\section{CONCLUSION AND OUTLOOK}

While research and application of EbA has increasingly gained attention from the international and local communities, the adoption and integration of this approach in natural resource management national development programme, planning and polices is still in an early stage. The Regional initiatives like the ENGAGE project serve to provide an example of dialogue and exchange between regional researchers and experts, and a platform for experiential learning for young professionals. The emphasis on the argument that, EbA and ICZM, if aligned, can also assist initiatives and 
commitments in the context of SDG13 (related to climate change), SDG14 (related to coastal and marine resources) and SDG17 (related to collaboration and partnerships) is among the central highlights of the project. It further elaborated on the EbA models and mechanisms of collaboration, participation and consultation, that diverse stakeholders, resource users and managers can adapt to achieving desired outcomes and impacts while implementing ICZM. The participants gained knowledge on integrated planning for coastal resources management, through deliberations on best EbA practices provided by a suite of expert and guest researchers.

During the project implementation, a discussion forum/web platform was created to facilitate dialogue, exchange knowledge and information, and address common queries on how climate change adaptation and EbA can be effectively integrated into coastal development planning and management. Discussions also emphasized practical and innovative solutions and methodologies for sustainable management of coastal ecosystems. The project was successful in promoting and encouraging EbA-related knowledge exchange between different stakeholders in the region. It was commonly agreed that the region can benefit from collaboration and exchange, participatory models of stakeholder's engagement and community empowerment, and promotion of integrated solutions such as EbA.

Key highlights of the ENGAGE project include:

Focusing on cooperation and collaboration of institutions for data exchange, building regional information on best management practices, and success and failure stories in the context of ecosystem services approaches to ICZM;

Steering collective efforts to build the capacity of regional stakeholders on current strategies, methods, and procedures for regional cooperation; and

Mapping gaps and needs towards strengthening capacity to adopt and implement ecosystem-based approach for management of coastal resources and building resilience of coastal communities.

\section{ACKNOWLEDGEMENTS}

We want to acknowledge the support from the AsiaPacific Network for Global Change Research (CBA201609SY-NGO) and Ms Lo Ly and Ly Mai Huong from AIT, Viet Nam for the valuable support during project implementation. We would also like to thank all participants of the programme and researchers from UNU INWEH who systematically contributed useful inputs during the implementation of the ENGAGE programme.

\section{REFERENCES}

Asian Development Bank. (2009). The Economics of Climate Change in Southeast Asia: A Regional Review.

Brown, K., Daw, T., Rosendo, S., Bunce, M., \& Cherrett, N. (2008). Ecosystem services for poverty alleviation: marine \& coastal situational analysis (synthesis report).

Burroughs, R. (2011). Coastal Governance. Washington, DC: Island Press.

Convention on Biological Diversity, 5 June 1992, 1760 UNTS. 79, Can. TS. 1993 No. 24, 31 ILM. 818 [CBD].

Food and Agriculture Organization of the United Nations. (2016). Final workshop for "Income for Coastal Communities for Mangrove Protection" Project. Retrieved from http://www.fao.org/fileadmin/ templates/rap/files/meetings/2016/161220_ Concept_note_and_agenda.pdf

Hens, L., Borden, R. J., Suzuki, S., \& Caravello, G. (Eds.). (1998). Proceedings of the symposium organized at the occasion of the VII International Congress of Ecology.

Hughes, A. C. (2017). Understanding the drivers of Southeast Asian biodiversity loss. Ecosphere, 8(1). http://doi.org/10.1002/ecs2.1624

Hung, N. T., Nagabhatla, N., Tuan, L. A., Kathiresan, K., \& Moon, S. (2017). Ecosystem Based Adaptation Approach for Sustainable Management and Governance of Coastal Ecosystems (ENGAGE): Technical Report.

Institute of Strategy and Policy on Natural Resources and Environment. (2013). Mainstreaming Ecosystembased Adaptation in Viet Nam.

Maes, J., \& Jacobs, S. (2017). Nature-Based Solutions for Europe's Sustainable Development. Conservation Letters, 1O(1), 121-124. http://doi.org/10.1111/conl.12216

McCue, J. (2014). Preparation of a Diagnostic Study to inform an Integrated Coastal Management Plan for Tongatapu, Tonga - Deliverable 3: Final Coastal Issues. Noumea.

Nagabhatla, N., \& Metcalfe, C. D. (Eds.). (2018). Multifunctional Wetlands: Pollution Abatement and Other Ecological Services from Natural and Constructed Wetlands. Cham: Springer International Publishing. http://doi.org/10.1007/978-3-319-67416-2

Nagabhatla, N., Sellamuttu, S. S., Bobba, A. G., Finlayson, M., Wickramasuriya, R., Van Brakel, M., ... Pattanaik, C. (2012). Insight to Ecosystem Based Approach (EBA) at Landscape Level Using a Geospatial Medium. Journal of the Indian Society of Remote Sensing, 40(1), 47-64. http://doi.org/10.1007/s12524-011-0080-8

Rebuelta, A. (2012). The implementation of the National Integrated Coastal Management Programme (ICMP) in the Philippines: Issues and Challenges.

Springate-Baginski, O., \& Blaikie, P. M. (2007). Forests, 
people and power: the political ecology of reform in South Asia. Earthscan. Retrieved from https://www. gov.uk/dfid-research-outputs/forests-people-andpower-the-political-ecology-of-reform-in-southasia

Tabet, L., \& Fanning, L. (2012). Integrated coastal zone management under authoritarian rule: An evaluation framework of coastal governance in Egypt. Ocean \& Coastal Management, 61, 1-9. http://doi. org/10.1016/j.ocecoaman.2012.01.006

UNCED, \& Johnson, S. P. (1993). The Earth Summit: the United Nations Conference on Environment and Development (UNCED). Boston: Martinus Nijhoff.

United Nations. (2011). Ecosystem-based approaches to adaptation: compilation of information.

UP-MSI, ABC, ARCBC, DENR, \& ASEAN. (2002). Marine Protected Areas in Southeast Asia. (P. Bridget \& W. R. dela Cruz, Eds.). Los Baños: ASEAN Regional Centre for Biodiversity Conservation - Department of Environment and Natural Resources.

Veron, J. E. E., \& Stafford, S. (2000). Corals of the World. Townsville: Australian Institute of Marine Science.

Visser, L. E. (2004). Challenging coasts : transdisciplinary excursions into integrated coastal zone development. Amsterdam University Press. Retrieved from https:// www.jstor.org/stable/j.ctt45kf21

Wilson, C., \& Tisdell, C. A. (2003). Conflicts over natural resources and the environment : economics and security (No. 86). Brisbane. 